\title{
Metal Ions and Hydroperoxide Content: Main Drivers of Coastal Lipid Autoxidation in Riverine Suspended Particulate Matter and Higher Plant Debris
}

\author{
Marie-Aimée Galeron ${ }^{1, *}$, Olivier Radakovitch ${ }^{2}$, Bruno Charrière ${ }^{3}$ and Jean-François Rontani ${ }^{1}$ \\ 1 Aix Marseille Université, Université de Toulon, CNRS, IRD, MIO UM 110, \\ Mediterranean Institute of Oceanography, 13288 Marseille, France; jean-francois.rontani@mio.osupytheas.fr \\ 2 CEREGE UM34, Aix Marseille Université, CNRS, IRD, CDF, 13545 Aix-en-provence, France; \\ radakovitch@cerege.fr \\ 3 Centre de Formation et de Recherche sur l'Environnement Méditerranéen (CEFREM, UMR CNRS 5110), \\ Bât. U, Université de Perpignan, Via Domitia (UPVD), 66860 Perpignan, France; \\ bruno.charriere@univ-perp.fr \\ * Correspondence: marie-aimee.galeron@mio.osupytheas.fr; Tel.: +33-4-8609-0521 \\ Academic Editor: Boris Peter Koch \\ Received: 30 May 2016; Accepted: 9 August 2016; Published: 23 August 2016
}

\begin{abstract}
Autoxidation is a complex abiotic degradation process, and while it has long been known and well studied in biological compounds, it has been widely overlooked in environmental samples and as a part of environmental processes. With recent observations showing the magnitude of the involvement of autoxidation in coastal environments, it has become critical to better understand how and why this degradative process takes place. At the riverine/marine interface, recent findings evidenced a spike in autoxidation rates upon the arrival of suspended particulate matter in seawater. In this study, we aimed at identifying autoxidation-favoring factors in vitro by analyzing suspended particulate matter incubated under different conditions. If metal ions have long been known to induce autoxidation in biological systems, we show that they indeed induce autoxidation in particulate matter incubated in water, but also that the content in photochemically-produced hydroperoxides in suspended particulate matter is crucial to the induction of its autoxidation in water.
\end{abstract}

Keywords: autoxidation; photo-oxidation; lipid tracers; organic matter degradation; suspended particulate matter; hydroperoxide

\section{Introduction}

Autoxidation is a free radical chain process. Such reactions can be divided into three stages: chain initiation, propagation, and termination. In the initiation process, enzymes, heat, light and metal ions may play a role in the generation of radicals. The metal ion-catalyzed homolytic cleavage of photochemically-produced hydroperoxides [1] has been suggested to play an important role in the initiation of autoxidation reactions in phytodetritus [2], although this has not been firmly established experimentally. The chain reaction ends when free radicals collide and exchange electrons to form a new bond, hence rendering them unreactive.

While lipid autoxidation has been extensively studied in medical and food sciences [3,4], it has been long overlooked in the environmental sciences, even though its impact on organic matter could be tremendous.

In estuarine and coastal areas, a better knowledge of the fate of river-transported particulate organic matter (POM) is essential for a better understanding of organic matter export, sedimentation rates, and ultimately coastal carbon cycles. It has been previously demonstrated that autoxidation is a major degradative process in rivers [5] and that it is enhanced upon the POM's arrival at sea [6]. 
While there can be a number of explanations for this phenomenon, it is critical that we understand what drives it in order to know if this is a localized phenomenon or a global occurrence.

It has been long known that transition metals can catalyze autoxidation in biological systems $[7,8]$, but could there be other drivers in the environmental systems? Is the presence of transition metal ions in freshwater and seawater enough to kickstart autoxidative chain reactions? What are the dynamics of these reactions in suspended particulate matter (SPM) in aquatic systems?

In previous observations in the Mackenzie River (Canada), it has been demonstrated that autoxidation acts intensely on POM reaching seawater, while it is fairly limited in the river [6]. These results also made apparent the crucial role of the photodegradation state of SPM on its future autoxidation, through the production of associated autoxidation-promoting hydroperoxides. With this work we aim to look at the importance of trace metal ions and hydroperoxide contents on the degradation of POM, in order to better understand the behavior of terrestrial organic matter reaching marine environments.

\section{Materials and Methods}

\subsection{Tracers Used}

In light of recent observations made in the Rhône River [5] and during in vitro experiments [9,10], we selected a set of lipid tracers allowing us to trace both the origin of SPM and the degradative processes undergone by lipids in SPM.

We selected 24-ethylcholest-5-en-3 $\beta$-ol (sitosterol if the C-24 stereochemistry is $24 \alpha$ ), lup-20(29)-en-3 $\beta, 28$-diol (betulin), urs-12-en-3 $\beta$-ol ( $\alpha$-amyrin) and olean-12-en-3 $\beta$-ol ( $\alpha$-amyrin) as lipids of interest, since we are also able to quantify their oxidation products and associate them with autoxidative processes (Figure 1). Betulin and both amyrins are also unambiguous tracers of terrestrial vascular plants $[9,10]$.

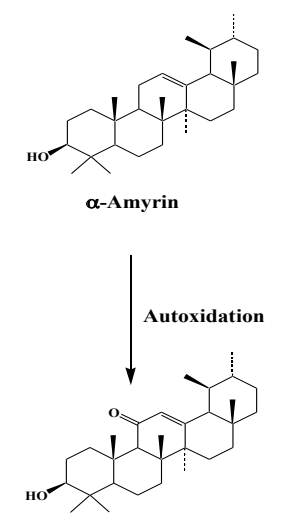

3ß-hydroxy-urs-12-en-11-one

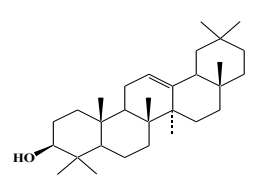

及-Amyrin

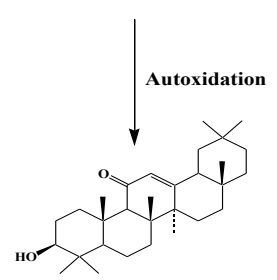

3ß-hydroxy-olean-12-en-11-one

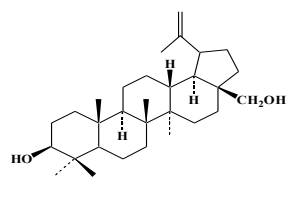

Betulin

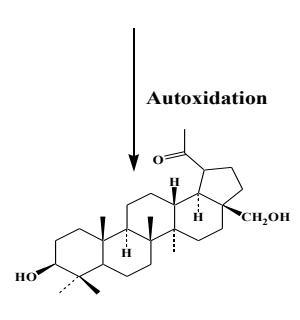

lupan-20-one-3ß,28-diol
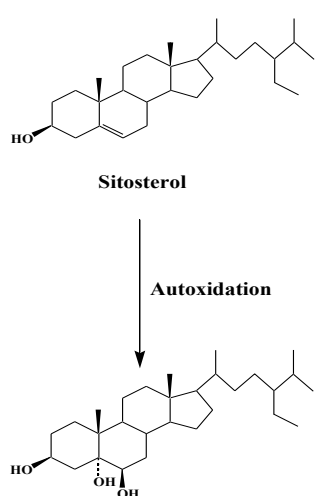

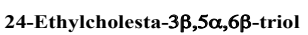

Figure 1. Proposed tracers of autoxidative damages in higher-plant material.

\subsection{Experimental}

\subsubsection{Rhône SPM Samples}

Samples of SPM were collected in the Rhône River (South of France), $30 \mathrm{~km}$ upstream from the river mouth (Figure 2), using a CEPA Z61 Teflon-coated centrifuge directly connected to the water stream. On the date sampled, the SPM Particulate Organic Carbon (POC) content was $6.8 \%$ (MOOSE data, www.moose-network.fr). Wet samples were finely ground and conserved at $4{ }^{\circ} \mathrm{C}$ prior to the experiments. SPM samples were incubated for 49 days under different conditions:

- Seawater

- Ultra-pure water 
- $\quad$ Ultra-pure water with added $\mathrm{Cu}^{2+}\left(2.4 \mu \mathrm{M}\right.$ of $\left.\mathrm{CuSO}_{4}\right)$

- Ultra-pure water with added $\mathrm{Fe}^{2+}(1.0 \mathrm{mM}$ of Mohr's salt)

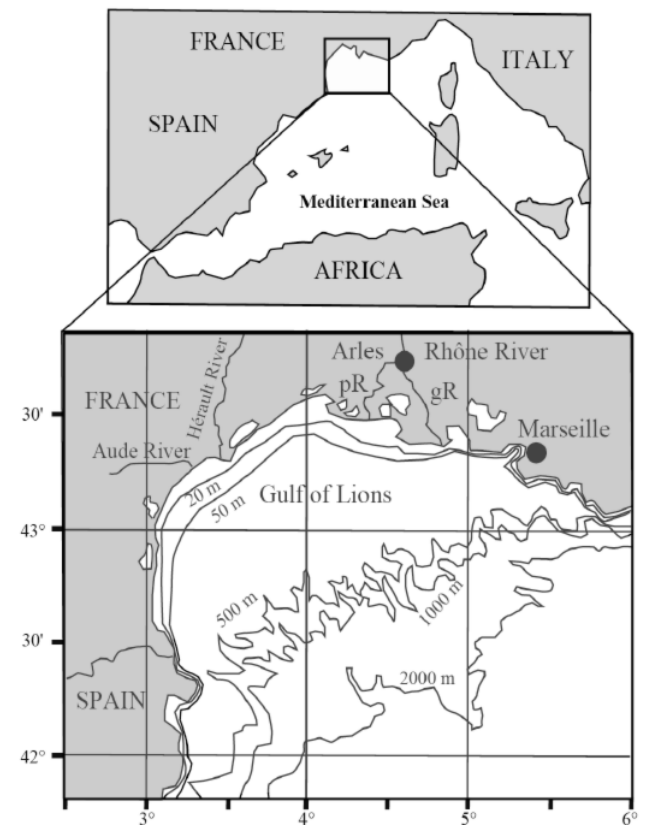

Figure 2. Rhone River mouth area and sampling locations: "Arles" and "Marseille". gR and pR mean grand Rhone and petit Rhone which are the two arms of the river.

These two metals were chosen because of their potential influence on autoxidation processes $[7,8]$ and the choice of metal ion concentrations was based on observations made by Ollivier et al. [11] in the Rhone River. Seawater (38 g/L) was collected in the Mediterranean Sea, three miles offshore from Marseille.

\subsubsection{Terrestrial Vascular Plant Samples}

Senescent leaves of Quercus ilex and Smilax aspera-both widespread species in Mediterranean ecosystems-were collected on the ground near Marseille, France. Samples were freeze-dried, ground to a fine powder, and kept at $4{ }^{\circ} \mathrm{C}$. Samples were incubated in ultra pure water with or without added $\mathrm{Fe}^{2+}$ ions, and analyzed after 39 and 103 days.

\subsubsection{Chemical Treatment of the Samples}

After filtration on GF/F glass fiber filters, samples were treated with excess $\mathrm{NaBH}_{4}$ in $\mathrm{MeOH}$ ( $25 \mathrm{~mL} ; 30 \mathrm{~min}$ ) to reduce labile hydroperoxides (resulting from photo- or autoxidation) to alcohols that were more amenable to analysis using GC-EIMS [12]. After $\mathrm{NaBH}_{4}$ reduction, water $(25 \mathrm{~mL})$ and $\mathrm{KOH}$ $(2.8 \mathrm{~g})$ were added and the resulting mixtures saponified under reflux $(2 \mathrm{~h})$. After cooling, the resulting solutions were acidified $(\mathrm{HCl}, 2 \mathrm{~N})$ to $\mathrm{pH} 1$ and extracted with dichloromethane $(\mathrm{DCM})(3 \times 20 \mathrm{~mL})$. The combined DCM extracts were dried over anhydrous $\mathrm{Na}_{2} \mathrm{SO}_{4}$, filtered, and concentrated by rotary evaporation $\left(40^{\circ} \mathrm{C}\right)$.

A different treatment was undergone by SPM sample (wet, or freeze-dried) in order to quantify the hydroperoxides present in the suspended particulate matter used for incubation [13]. Samples were extracted three times with chloroform- $\mathrm{MeOH}-\mathrm{H}_{2} \mathrm{O}(1: 2: 0.8$, v:v:v) using ultrasonication. The supernatant was separated by centrifugation at $3500 \times g$ for $9 \mathrm{~min}$. To initiate phase separation, purified $\mathrm{H}_{2} \mathrm{O}$ was added to the combined extracts to give a final volume ratio of 1:1 (v:v). The upper aqueous phase was extracted three times with DCM and the combined DCM extracts were filtered and the solvent removed via rotary evaporation. The residue obtained after extraction was dissolved in 
$5 \mathrm{~mL}$ of DCM and separated in two equal subsamples. After evaporation of the solvent, degradation products were obtained for the first subsample after acetylation (inducing complete conversion of hydroperoxides to the corresponding ketones [14]) and saponification and for the second after reduction with $\mathrm{NaBD}_{4}$ and saponification. After saponification, the samples were then acidified, extracted and concentrated as previously described.

\section{Results}

Because sitosterol alone cannot be unambiguously attributed to organic matter of terrestrial origin (possible production by freshwater plankton [5]), we have compared its autoxidation rates to those of other compounds of a more clearly terrestrial origin. In all incubations, we determined autoxidative degradation rates for three families of lipid tracers: sitosterol, $\alpha-/ \beta$-amyrins, and betulin.

\subsection{Rhone SPM Incubations}

In SPM incubations, it appears clear that the degradation rates of the compounds studied vary greatly. In the Rhone SPM, sitosterol is particularly reactive, and the addition of metal ions into the incubations has a marked effect on its autoxidation rates, going from $2.6 \% \pm 0.4 \%$ at the beginning of the experiment to $8.0 \% \pm 1.2 \%$ after 49 days in ultrapure water with added $\mathrm{Cu}^{2+}$ ions, $10.6 \% \pm 0.7 \%$ in seawater, and even $18.2 \% \pm 2.1 \%$ in ultrapure water with added $\mathrm{Fe}^{2+}$ ions (Figure $3 \mathrm{~A}$ ).
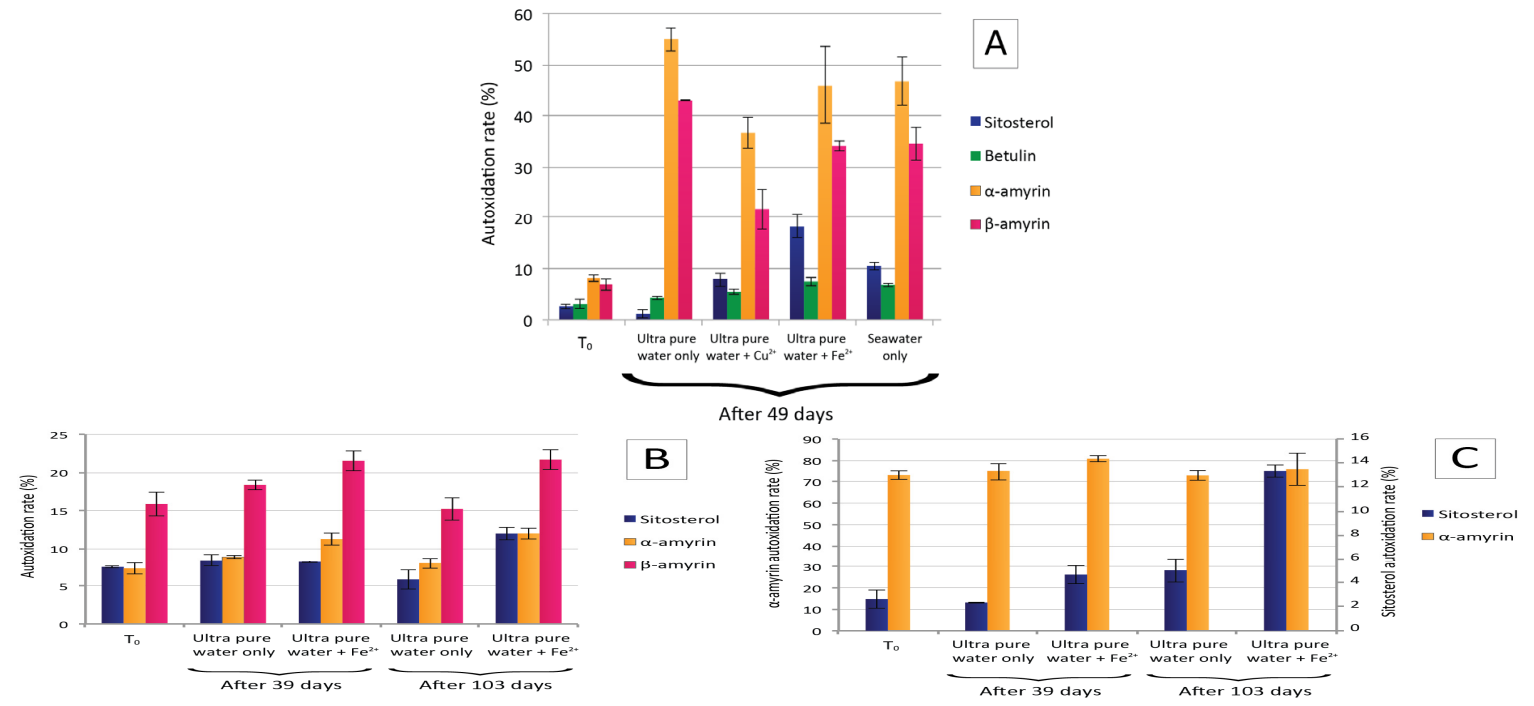

Figure 3. Autoxidation rates (calculated using the following ratio: oxidation product/(parent compound + total of oxidation products quantified) of the studied compounds in SPM incubations for the Rhone River (A); and in Quercus ilex (B) and Smilax aspera (C) plant debris incubations.

Betulin, on the other hand, is slower to react and the observed increase of autoxidation rates with added metal ions is not as dramatic as that of sitosterol. The addition of metal ions still had a significant effect on its autoxidation rates. The addition of $\mathrm{Fe}^{2+}$ brought its starting autoxidation rate of $3.1 \% \pm 0.8 \%$ to $7.5 \% \pm 0.8 \%$ after 49 days (compared to the $5.5 \% \pm 0.4 \%$ observed in ultrapure water with added $\mathrm{Cu}^{2+}$ ions, and $6.8 \% \pm 0.3 \%$ in seawater after 49 days; Figure $\left.3 \mathrm{~A}\right)$. In fact, the addition of $\mathrm{Fe}^{2+}$ seems to bring up betulin autoxidation rates to a level close to the one they are at in seawater.

The $\alpha$ - and $\beta$-amyrins, however, showed variable autoxidation rates. In incubated SPM from the Rhône, autoxidation rates for both amyrins seem to be going down after 49 days (regardless of the conditions), with rates when extra $\mathrm{Cu}^{2+}$ was added being the lowest with $36.7 \% \pm 2.7 \%$ and $21.8 \% \pm 3.6 \%$ for $\alpha$ - and $\beta$-amyrins, respectively (compared to their $\mathrm{T}_{0}$ levels of autoxidation of $8.3 \% \pm 0.7 \%$ and $7.0 \% \pm 1 \%$, respectively). It is important to note that the starting autoxidation rates of amyrins were higher than those of sitosterol and betulin. 
The $\alpha$-amyrin is more degraded than its $\beta$ counterpart after 49 days, but individual rates are similar whether particulate matter was incubated in ultrapure water with added $\mathrm{Fe}^{2+}$ ions or in seawater.

Analyzed lipid extracts obtained from SPM from the Rhone River allowed us to calculate the proportion of sitosterol-derived hydroperoxides in the SPM used for the incubations. In the Rhone SPM, these hydroperoxides represent $2.96 \% \pm 0.19 \%$ of sitosterol (Figure 4 ).

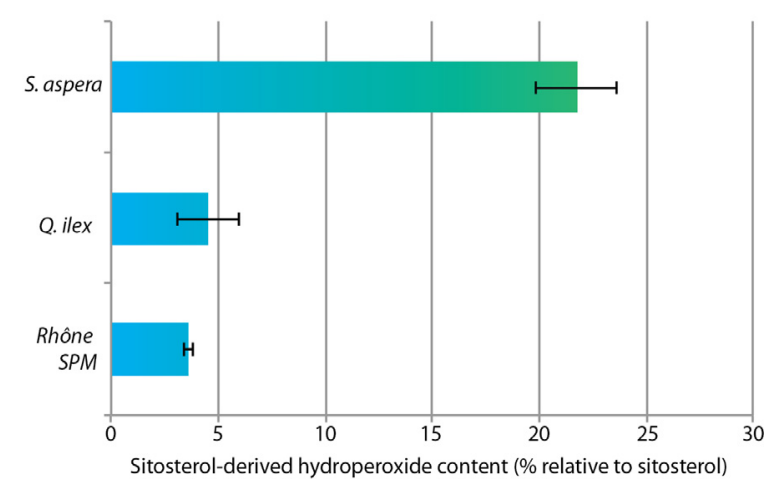

Figure 4. Relative percentages of intact sitosterol-derived hydroperoxides (relative to residual sitosterol) in the different materials used for incubation at $\mathrm{T}_{0}$ : Smilax aspera (S. aspera) or Quercus ilex (Q. ilex) senescent leaves, and Rhône SPM.

\subsection{Plant Debris Incubations}

Since SPM collected in rivers has a partially terrestrial origin, we also collected senescent plant material (leaf material from Quercus ilex and Smilax aspera) in order to have it undergo the same incubation treatment. Based on the previous results, with this experiment we aimed to show the role of metal ions and hydroperoxide content in the induction of autoxidative reactions in larger-sized organic matter of terrestrial origin.

While betulin and its oxidation products were below detection levels, we were able to quantify autoxidation rates for sitosterol, $\alpha$-amyrin and $\beta$-amyrin. However, in $S$. aspera samples, $\beta$-amyrin seemed to be co-eluted with an unknown compound; for that reason and in order to be as precise as possible, we will not be looking at its degradation products in S. aspera incubations.

The effect of metal ions on autoxidation rates appeared to be more evident in the case of S. aspera, where the autoxidation rate of sitosterol went from $2.6 \% \pm 1 \%$ at the beginning of the experiment to $4.7 \% \pm 0.9 \%$ after 39 days and $13.3 \% \pm 0.6 \%$ after 103 days (versus $2.3 \% \pm 0.1$ and $5.0 \% \pm 1.1 \%$, respectively, without added $\mathrm{Fe}^{2+}$ ions; Figure $3 \mathrm{C}$ ). This effect can also be seen in the autoxidation rates of $\alpha$-amyrin (going from $72.7 \% \pm 2 \%$ at the beginning of the experiment to $75.1 \% \pm 4 \%$ after 39 days incubated in ultrapure water and $80.1 \% \pm 1.5 \%$ when $\mathrm{Fe}^{2+}$ ions were added).

When $Q$. ilex leaves were incubated, metal ions seemed to take longer to have an effect on autoxidation, with a starting autoxidation rate of $7.5 \% \pm 0.1 \%$ for sitosterol only increasing to $8.2 \% \pm 0.1 \%$ after 39 days, but climbing to $12.0 \% \pm 0.8 \%$ after 103 days (Figure 3B). For $\alpha-$ and $\beta$-amyrins, the effect of added $\mathrm{Fe}^{2+}$ ions was significant on their autoxidation rates, with $\alpha$-amyrin autoxidation rates going from $7.3 \% \pm 0.7 \%$ to $11.3 \% \pm 0.8 \%$ and $12.0 \% \pm 0.7 \%$ after 39 and 103 days, respectively, when $\mathrm{Fe}^{2+}$ ions were added to the incubation. The $\beta$-amyrin, on the other hand, saw its autoxidation rate increasing from $15.9 \% \pm 1.5 \%$ to $21.5 \% \pm 1.3 \%$ and $21.7 \% \pm 1.3 \%$ after incubation for 39 and 103 days, respectively, when $\mathrm{Fe}^{2+}$ ions were added.

As previously explained, we also quantified sitosterol-related hydroperoxides. The hydroperoxide content of the leaf debris sampled also seemed to greatly influence the level of autoxidation observed in the incubations. S. aspera had the highest hydroperoxide content, representing $18.07 \% \pm 1.56 \%$ of sitosterol, while they represented only $3.74 \% \pm 1.2 \%$ of sitosterol in $Q$. ilex leaf debris. 


\section{Discussion}

\subsection{Rhone River SPM Incubations}

With the recent observations made in situ on both the Rhône and the Mackenzie Rivers, where it has been demonstrated that autoxidation is a major degradative process $[5,6]$, we expected betulin, sitosterol and $\alpha$ - and $\beta$-amyrins to be fairly autoxidized, even at the start of our experiment. The observed state of degradation of the incubated SPM is in line with those results, clearly indicating that whether we are looking at particles or leaf debris, autoxidation has been involved in their degradation, whether on land or during riverine transport.

Also, because of the set of lipid tracers used, it is clear that the autoxidative processes observed acted on SPM of terrestrial origin $[9,10]$. It has been demonstrated that autoxidation is induced when particulate matter is incubated in seawater, and this was explained by the potential desorption of metallic ions upon contact with seawater [6].

The observed effect of metal ions on the induction of autoxidation seems to confirm this hypothesis. It appears that the presence of $\mathrm{Fe}^{2+}$ and $\mathrm{Cu}^{2+}$ ions has a significant effect on the autoxidation rates of suspended particulate matter.

Previous results obtained in the Rhône [5] and Mackenzie [6] Rivers clearly showed that the SPM of terrestrial origin found in major coastal rivers has been intensely autoxidized even before reaching the ocean, but the results obtained in this study confirm that metal ions present in the water have favored this autoxidation, and will favor it in seawater. In coastal environments, it is possible that the metal ions necessary to induce this autoxidation could be desorbed from SPM upon its arrival at sea $[15,16]$. To confirm this hypothesis, in situ samples and metal ion concentrations are currently being studied.

\subsection{Leaf Debris Incubations}

Similar results were obtained when incubating leaf debris from Q. ilex and S. aspera. While it is clear that leaves underwent photo-oxidation while on land, the debris were also significantly autoxidized, whether this happened while still on land, or once in riverine waters. When incubated with added $\mathrm{Fe}^{2+}$ ions, autoxidation was clearly favored when compared to samples without the added metal ions. Here again, the results are similar to those obtained with incubated SPM, confirming the hypothesis that metal ions favor autoxidation in incubated plant debris.

\subsection{Hydroperoxide Content}

Even if our observations confirm the effect of metal ions on autoxidation, it appears they are not the sole driver of autoxidative processes. Indeed, the quantity of hydroperoxides present in SPM plays a major role in the induction of autoxidative processes, as previously reported by Rontani et al. [6].

Our quantification of hydroperoxides deriving from sitosterol oxidation products $(7 \alpha$-Hydroperoxy24-ethylcholest-5-en-3 $\beta$-ol, 6 $\beta$-Hydroperoxy-24-ethylcholest-4-en-3 $\beta$-ol, 7 $\beta$-Hydroperoxy-24-ethylcholest5-en-3 $\beta$-ol and $6 \alpha$-Hydroperoxy-24-ethylcholest-4-en-3 $\beta$-ol) showed that very different hydroperoxide profiles are observed for the different materials sampled and incubated, whether they are leaf debris or riverine SPM. The starting hydroperoxide content and sitosterol's final autoxidative rates (with added metal ions) are well correlated $\left(r^{2}=0.87, p<0.05\right)$, implying that the presence of metal ions can indeed be a factor inducing autoxidation, but it seems very well coupled with the SPM hydroperoxide content.

\subsection{Environmental Implications}

Scientists have understood the implications of carbon behavior in natural environments very early on, and visualized carbon dynamics as early as 1956 [17]. Through the years, carbon cycles have been completed, reservoirs and fluxes were better estimated, and their implications on global change well defined [18-21]. However, in the official carbon cycle representation used by the IPCC (Intergovernmental Panel on Climate Change), river to ocean fluxes and coastal exports to the deep 
ocean have not been re-estimated since 2002 [21,22]. Our findings, if they can be evidenced in natural environments on a global scale, could help redefine these fluxes and would lead to a better estimation of carbon exports and coastal burial.

\section{Conclusions}

The fact that metal ions can induce autoxidation has been discussed in the past [7,8], but the interest of this hypothesis has never been questioned for environmental samples. Due to the observation that SPM autoxidation rates spike when SPM is incubated in seawater [6], this hypothesis was again formulated for natural environments, and, in this study, tested in vitro. Our study confirms that metal ions do indeed favor autoxidation on SPM of riverine origin, but also that the presence of hydroperoxides resulting from photo-oxidative processes is another major driver of autoxidation in SPM. Moreover, our results on leaf debris validate the role of metals and the initial photo-oxidation state (i.e., hydroperoxide content) of the organic matter in the initiation of autoxidation processes. A better consideration of these abiotic degradative processes is a major issue in the understanding of the fate of terrestrial organic matter in coastal environments. In order to confirm the effect of this conjunction of factors in the environment, further tests and in situ sampling will be necessary.

Acknowledgments: This work is a contribution to the Labex OT-Med ( $\mathrm{n}^{\circ}$ ANR-11-LABX-0061) funded by the French Government "Investissements d'Avenir" program of the French National Research Agency (ANR) through the $A^{*}$ MIDEX project ( ${ }^{\circ}$ ANR-11-IDEX-0001-02). It was supported by the LEFE-CYBER national program, as part of the MORTIMER research program and undergone as part of the transversal research axis DEBAT of the Mediterranean Institute of Oceanography, Marseille, France. Additional data was provided by "MOOSE" (Mediterranean Oceanic Observing System for the Environment) with the support of the "Agence de l'Eau Rhone-Méditerranée-Corse". Special thanks to Michel Fornier for providing samples.

Author Contributions: Marie-Aimée Galeron, Olivier Radakovitch and Jean-François Rontani conceived and designed the experiments; Marie-Aimée Galeron and Bruno Charrière performed the experiments; Marie-Aimée Galeron and Jean-François Rontani analyzed the data; Marie-Aimée Galeron played the lead role in writing the paper, to which all authors contributed.

Conflicts of Interest: The authors declare no conflict of interest.

\section{References}

1. Schaich, K.M. Lipid oxidation: Theoretical aspects. In Bailey's Industrial Oil and Fat Products, 6th ed.; Wiley: New York, NY, USA, 2005; pp. 269-355.

2. Rontani, J.-F.; Rabourdin, A.; Marchand, D.; Aubert, C. Photochemical oxidation and autoxidation of chlorophyll phytyl side chain in senescent phytoplanktonic cells: Potential sources of several acyclic isoprenoid compounds in the marine environment. Lipids 2003, 38, 241-254. [CrossRef] [PubMed]

3. Simic, M.G.; Karel, M. Autoxidation in Food and Biological Systems; Springer: New York, NY, USA, 1980.

4. Stocks, J.; Dormandy, T.L. The autoxidation of human red cell lipids induced by hydrogen peroxide. Br. J. Haematol. 1971, 20, 95-111. [CrossRef] [PubMed]

5. Galeron, M.-A.; Amiraux, R.; Charrière, B.; Radakovitch, O.; Raimbault, P.; Garcia, N.; Lagadec, V.; Vaultier, F.; Rontani, J.-F. Seasonal survey of the composition and degradation state of particulate organic matter in the Rhône River using lipid tracers. Biogeosciences 2015, 12, 1431-1446. [CrossRef]

6. Rontani, J.-F.; Charrière, B.; Sempéré, R.; Doxaran, D.; Vaultier, F.; Vonk, J.E.; Volkman, J.K. Degradation of sterols and terrigenous organic matter in waters of the Mackenzie Shelf, Canadian Arctic. Org. Geochem. 2014, 75, 61-73. [CrossRef]

7. Bawn, C.E.H. Free radical reactions in solution initiated by heavy metal ions. Discuss. Faraday Soc. 1953, 14, 181-190. [CrossRef]

8. Miller, D.M.; Buettner, G.R.; Aust, S.D. Transition metals as catalysts of 'autoxidation' reactions. Free Radic. Biol. Med. 1990, 8, 95-108. [CrossRef]

9. Galeron, M.-A.; Vaultier, F.; Rontani, J.-F. Oxidation products of $\alpha$ - and $\beta$-amyrins: Potential tracers of abiotic degradation of vascular plant organic matter in aquatic environments. Environ. Chem. 2016, 13, 732-744. [CrossRef] 
10. Galeron, M.-A.; Volkman, J.K.; Rontani, J.-F. Oxidation products of betulin: New tracers of abiotic degradation of higher plant material in the environment. Org. Geochem. 2016, 91, 31-42. [CrossRef]

11. Ollivier, P.; Radakovitch, O.; Hamelin, B. Major and trace element partition and fluxes in the Rhône River. Chem. Geol. 2011, 285, 15-31. [CrossRef]

12. Marchand, D.; Rontani, J.-F. Characterization of photo-oxidation and autoxidation products of phytoplanktonic monounsaturated fatty acids in marine particulate matter and recent sediments. Org. Geochem. 2001, 32, 287-304. [CrossRef]

13. Rontani, J.-F.; Charrière, B.; Forest, A.; Heussner, S.; Vaultier, F.; Petit, M.; Delsaut, N.; Fortier, L.; Sempéré, R. Intense photooxidative degradation of planktonic and bacterial lipids in sinking particles collected with sediment traps across the Canadian Beaufort Shelf (Arctic Ocean). Biogeosciences 2012, 9, 4787-4802. [CrossRef]

14. Mihara, S.; Tateba, H. Photosensitized oxygenation reactions of phytol and its derivatives. J. Org. Chem. 1986, 51, 1142-1144. [CrossRef]

15. Shulkin, V.; Bogdanova, N. Mobilization of metals from riverine suspended matter in seawater. Mar. Chem. 2003, 83, 157-167. [CrossRef]

16. Milward, G.E.; Liu, Y.P. Modelling metal desorptions kinetics in estuaries. Sci. Total Environ. 2003, 314-316, 613-623. [CrossRef]

17. Eriksson, E.; Welander, P. On a mathematical model of the carbon cycle in nature. Tellus 1956, 8, 155-175. [CrossRef]

18. Baes, C.F.J.; Goeller, H.E.; Olson, J.S.; Rotty, R.M. Global Carbon Dioxide Problem. 1976 (An Oak Ridge National Lab. (TN) Report (USA)). Available online: http://www.osti.gov/scitech/biblio/7145150 (accessed on 20 May 2016).

19. Baes, C.F.; Goeller, H.E.; Olson, J.S.; Rotty, R.M. Carbon dioxide and climate: The uncontrolled experiment: Possibly severe consequences of growing $\mathrm{CO}_{2}$ release from fossil fuels require a much better understanding of the carbon cycle, climate change, and the resulting impacts on the atmosphere. Am. Sci. 1977, 65, 310-320.

20. Sundquist, E.T. The global carbon dioxide budget. Science 1993, 259, 934-941. [CrossRef]

21. Solomon, S.; Qin, D.; Manning, M.; Chen, Z.; Marquis, M.; Averyt, K.B.; Tignor, M.; Miller, H.L. Contribution of Working Group I to the Fourth Assessment Report of the Intergovernmental Panel on Climate Change. 2007. Available online: https://www.ipcc.ch/publications_and_data/publications_ipcc_fourth_assessment_ report_synthesis_report.htm (accessed on 19 May 2016).

22. Sarmiento, J.L.; Gruber, N. Sinks for Anthropogenic Carbon. Phys. Today 2002, 55, 30-36. [CrossRef] 